\title{
EXPERIMENTAL CORONARY ARTERIOGRAPHY BY SINGLE X-RAY EXPOSURE*
}

\author{
BY \\ CONWAY DON, GEORGE A. BOUSVAROS, $\uparrow$ JOHN A. HOPPS, AND O. Z. ROY \\ From the Departments of Radiology, University of Ottawa and Ottawa General Hospital, and the Medical Electronics \\ Group, the National Research Council of Canada, Ottawa, Canada \\ Received July 7, 1961 \\ Methods for opacification of the coronary arteries in vivo have been extensively investigated in \\ recent years, stimulated by the development of direct coronary vascular surgery. Cardioangio- \\ graphy or cineradiography has been used with injection of the opaque medium into the root of the \\ aorta or into the coronary arteries themselves (Sones, 1960). Cardiac arrest with acetylcholine \\ has also been advocated (Arnulf and Chacornac, 1958; Anlyan et al., 1959; Sloman and Jefferson, \\ 1960), supplemented by balloon occlusion of the ascending aorta (Frische and Dotter, 1959). \\ Davies and Michell (1960) without arresting the heart were able to obtain adequate visualization \\ of the coronary arteries in dogs on a single film taken at the end of diastole. In the present report \\ a technique will be described, providing a reasonably simple method for coronary arteriography \\ in dogs; although not radically different from others, it incorporates a number of features that do \\ not seem to have been used previously in combination.
}

\section{METHOD}

Over 130 injections have been made in 30 dogs weighing between 20 and $40 \mathrm{~kg}$. For the procedure the animals were anæsthetized with pentobarbital $30 \mathrm{mg}$. per kg. of body weight. A radiopaque No. 205 polythene catheter of internal diameter $1.55 \mathrm{~mm}$. (Ödman, 1956) was introduced percutaneously from the femoral artery and advanced under fluoroscopic control into the root of the aorta. The proximal end had been preshaped into a clockwise (as seen from below) semicircular loop, the plane of which formed an obtuse angle with the shaft. The end hole was restricted over a No. 160 guide, in order to encourage flow through a single side hole, which had been punched laterally, 45 degrees below the plane of the loop and at a distance of $15 \mathrm{~mm}$. from the tip.

The injection of the opaque medium was performed by a Gidlund pressure injection apparatus and was initiated from the $R$ wave of the electrocardiogram by means of an electronic device, details of which have been presented elsewhere (Hopps et al., 1961). This device also allows triggering of the X-ray exposure at any desired interval following the initiation of the injection. From a consideration of the heart rate it was thus possible to trigger the X-ray exposure at any desired point of the succeeding two or three cardiac cycles.

For technical reasons $15 \mathrm{ml}$. of the opaque medium (50\% hypaque) were employed irrespective of the size of the animal, amounting to $0.3 \mathrm{ml}$. per $\mathrm{kg}$. for the larger dogs. The pressure of injection was $10 \mathrm{~kg}$. per sq. $\mathrm{cm}$. and the approximate duration of the injection for the $15 \mathrm{ml}$. was 0.8 seconds. Four to five injections, at intervals of about 15 minutes, were given in one session and in a few animals the procedure was repeated after 6 to 8 weeks.

The X-ray film was taken at the end of the 2nd or 3rd diastole from the start of the injection and

* Supported by a grant from the Ontario Heart Foundation and the National Health Grants Administration, Canada. $\dagger$ In receipt of a research travelling grant from the Wellcome Trust, London, England. 
at the left anterior oblique position, as previous experience with human and canine post-mortem arteriograms had shown that this or the right anterior oblique gave maximal spread of the coronary arteries. The electrocardiogram, duration of the syringe piston movement, timing of the exposure, and in several cases the intra-aortic pressure were recorded by a multichannel apparatus. At the end of the procedure the catheter was removed and the arterial opening obliterated by finger pressure for 5 minutes and then by compressive bandage.

\section{RESULTS}

A typical arteriogram in late diastole is shown in Fig. 1. Proximal and distal coronary artery filling is seen, but the short main stem and the bifurcation of the left coronary are obscured by the root of the aorta. These may be visualized on an early systolic film immediately after termination of the injection, when the opaque medium is partly washed from the aorta but not from the proximal left coronary artery (Fig. 2). As the importance of various factors, such as position and orientation of the end loop, rate of injection, timing of the exposure, etc., was only gradually appreciated

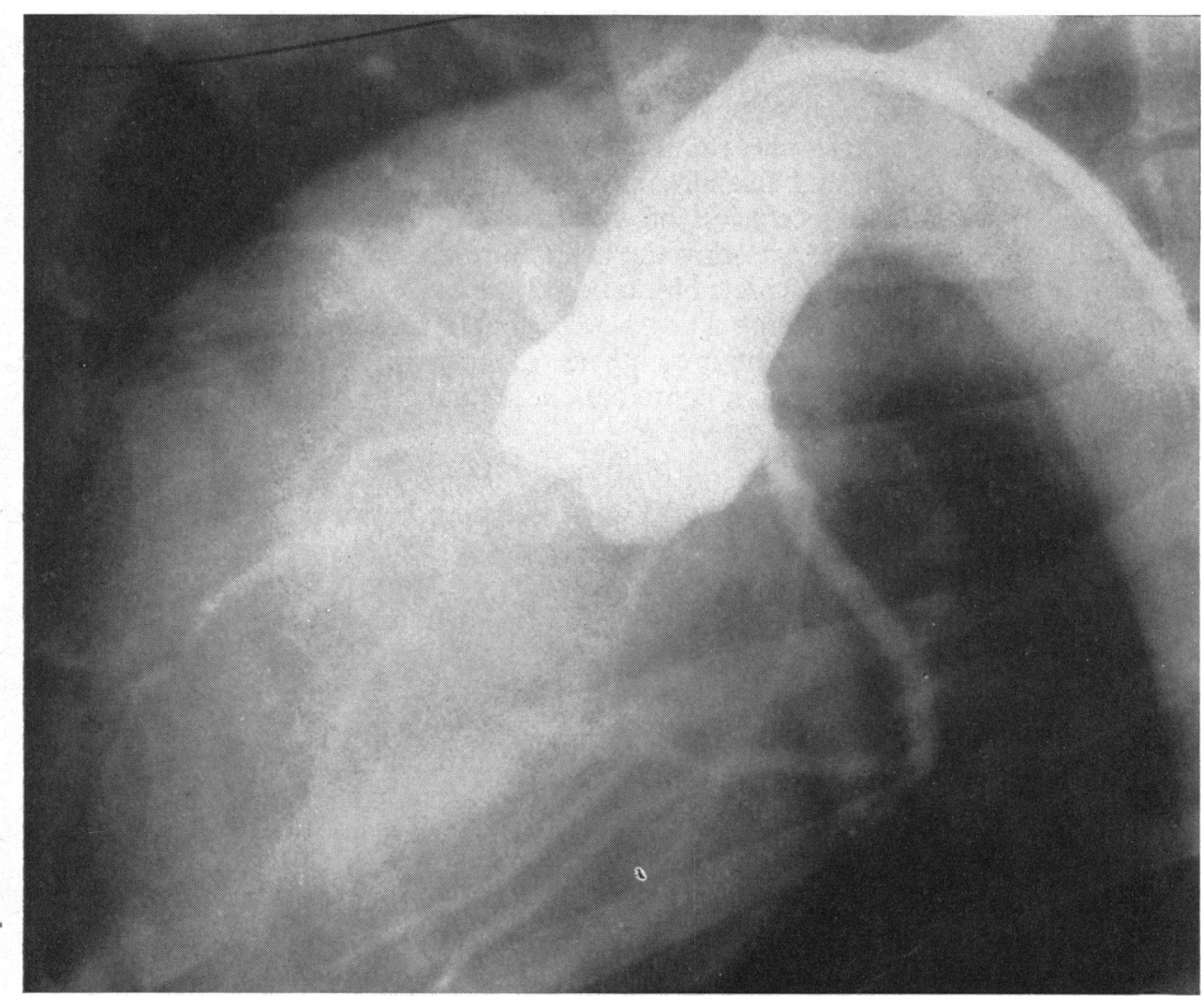

FIG. 1.-Coronary arteriogram in the left anterior oblique position and at the final third of the second diastole (heart rate 160 per minute). The right coronary artery is seen arising above the sinuses of Valsalva, the small vessel below it being probably the septal coronary artery (Blair, 1961). The proximal left coronary stem and the bifurcation are not seen, being obscured by the opacified root of the aorta.

poor arteriograms were often obtained initially. Later, when these details were meticulously observed, we had no failures except that improper filling of the branches of the right coronary was not unusual because of their small caliber (Nelson et al., 1960; Blair, 1961). 


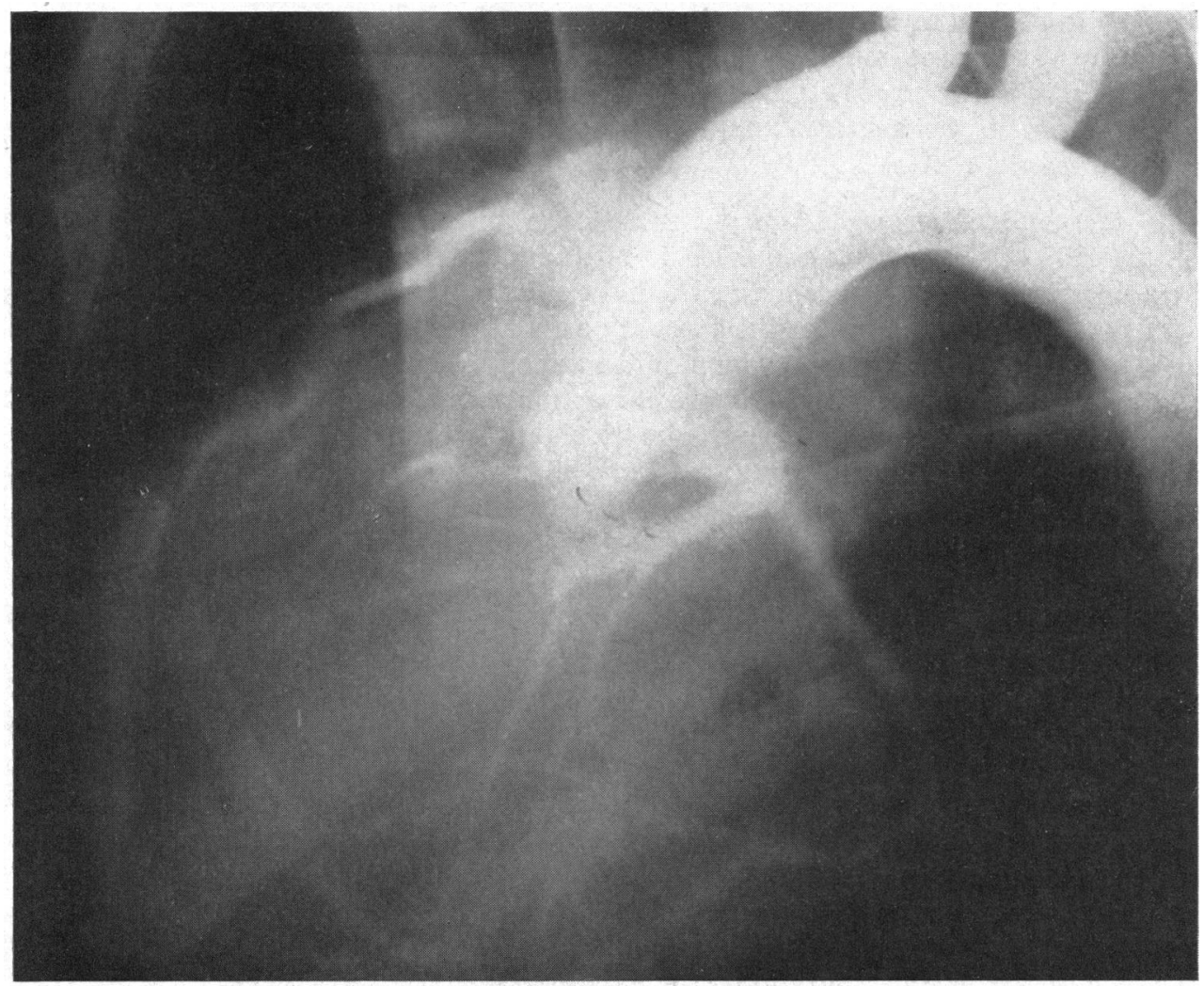

FIG. 2.-Early systolic film in the cycle following the end of the injection. The main left coronary artery and its bifurcation are no longer obscured by contrast medium in the left sinus of Valsalva.

\section{Discussion}

Percutaneous Introduction of the Catheter. This simple technique (Seldinger, 1953) has not been extensively used in coronary arteriography. Lang and Sabiston (1961) obtained poor arteriograms in 7 of 8 patients and concluded that the long catheter required for femoral percutaneous insertion involved too high frictional resistance for optimal rate of injection of 90 per cent hypaque. Williams et al. (1960) and Littmann et al. (1961) also used the percutaneous route and reported satisfactory coronary opacification, although the contrast material was injected by hand and therefore relatively slowly ( 3 to 5 seconds). This indicates that other factors, such as position and shape of the tip of the catheter, contributed to the poor results of Lang and Sabiston (1961). On the other hand the fast injection obtained in our experiments with the mechanical injector and less concentrated, and therefore less viscous, contrast medium is, we think, the cause of the better quality of our arteriograms compared to those illustrated by Williams et al. (1960) and Littman et al. (1961).

Use of Radiopaque Catheters. The internal diameter of the catheter is a significant determinant of the speed of injection, as the resistance to flow is inversely related to the fourth power of the radius (Poiseuille's law). The largest woven catheters, of bore up to $3 \mathrm{~mm}$. (Bishop and O'Laughlin, 1961), have therefore been used. Radiolucent rather than radiopaque polythene catheters have also been employed (Williams et al., 1960; Littmann et al., 1961) because of their thin wall and comparatively larger internal diameter. Since adequate rate of flow was obtained in our study by 
means of the mechanical injector, we continued to use radiopaque catheters as they provided better visibility allowing prompt manipulations and corresponding decrease of radiation exposure. Furthermore, injection of small quantities of dye, necessary with the radiolucent catheters during their final positioning, was avoided, and the fluoroscopic impression of the position of the catheter could be recorded on a scout film.

Shape and Orientation of the End Loop. Presence of an end hole for the percutaneous insertion may lead to recoil of the catheter and often to regurgitation into the left ventricle, as the jet of the opaque medium is directed towards the centre of the valve. To avoid these and to ensure maximum delivery of the opaque medium near the coronary ostia an end loop was fashioned, as proposed by Bellman et al. (1960), with the following modifications: first, a semicircular rather than a circular loop was formed, since only two out of the three sinuses of Valsalva need be injected. For the same reason one side hole was made to irrigate the right aortic sinus, while the stream from the end hole was directed into the left. Second, the plane of the loop was orientated at 120 to 140 degrees and not at right angles to the shaft, since at right angles the tip was often deflected upward, and the contrast material coming out of the end hole was lost into the aortic arch.

Low Concentration of Opaque Medium. The 50 per cent concentration of sodium diatrizoate, selected for its low viscosity and minimal toxicity, provided excellent opacification, so that there was no need for more concentrated media, the advantages of which in terms of degree of opacity have been questioned (Lehman and Debbas, 1961).

Timing of the Exposure. In the first cardiac cycle following the beginning of the injection, proximal coronary artery filling alone was obtained. Both proximal and distal filling occurred in the subsequent cycle, and the single X-ray film was therefore taken at the final third of the second diastole. With rates higher than 180 a minute three cardiac cycles were required for coronary opacification and the exposure was present for the end of the third diastole. Triggering of the $\mathrm{X}$-ray machine at the quiescent period of the cardiac cycle allowed sharp pictures, even with relatively slow exposures. With exposure durations $1 / 30$ th of a second or less unblurred pictures could be obtained in systole and this enabled visualization of the proximal left coronary artery (Fig. 2).

Devices for triggering of the X-ray exposure from the electrocardiogram have been explored by several groups of investigators (Hase and Deterling, 1957; Richards and Thal, 1958; Bellman et al., 1960; Davies and Michell, 1960; Boucek et al., 1961; Jackson and Cobbold, 1961; Sekelj et al., 1961).

Reactions and Mortality. One animal developed fatal ventricular fibrillation after injection of the test dose, probably due to hypersensitivity. Large total amount of pentobarbital ( $50 \mathrm{mg}$. per kg.), which was required to keep this particular animal anæsthetized may have predisposed to this unusual reaction. An identical reaction in man has been reported by Gurewich et al. (1961).

Transient ischæmic changes in the electrocardiogram, commonly observed by most authors, were very unusual in this series and have been noted only four times. It is probable that the low incidence of cardiographic changes is related to the low amount and concentration of opaque medium used, which did not significantly interfere with myocardial blood supply.

A second animal died two weeks after the procedure and at autopsy thrombotic occlusion of the right coronary ostium was found. This occurred in the very first animal of the series in which the catheter was perfused by nonheparinized saline; subsequently heparin was added to the infusion and no further instances were encountered. A case of posterior infarction after the procedure has also been reported by Williams et al. (1960). Five more animals died 1 to 12 days after the test. In three the cause of death was respiratory infection, probably due to the prolonged general anæsthesia, and in the other two hæmorrhage from the site of the arterial puncture; the superficial course of the femoral artery with lack of supportive tissue in the dog, restlessness of the animals and the large size of the arterial opening compared to the caliber of the vessel were probable contributory factors. 


\section{CoNClusions}

The above experiments demonstrate the adequacy of the described method for coronary arteriography in the dog and also suggest that it should be suitable for man. Percutaneous introduction and use of radiopaque catheter made the preliminary stages quite simple and the automatic triggering device allowed the use of simple routine X-ray equipment. The quality and detail of the single film may outweigh the advantage of the dynamic picture offered by cineangiography: comparison of the two methods is currently in progress. Biplane angiocardiographic equipment was not available to us; apart from providing pictures at two planes, it would also eliminate the need for a triggering device, provided the frequency is over 5 frames per second.

The risk of this procedure should be small in man, as the dose of the contrast material per $\mathrm{kg}$. of body weight should be smaller than in the dogs and not more than two injections will be required. Deaths due to respiratory infection, or to hæmorrhage from the arterial puncture should not occur. The unexpected fatality from ventricular fibrillation, as possible manifestation of drug idiosyncrasy, nevertheless suggests that the procedure should be undertaken in the presence of very strict indications and in surroundings equipped to handle cardiovascular emergencies.

\section{SUMMARY}

A method is described by means of which satisfactory coronary arteriograms were obtained in the dog. It consists in mechanical injection of approximately $0.3 \mathrm{ml}$. per $\mathrm{kg}$. of body weight of 50 per cent sodium diatrizoate through a radiopaque polythene catheter introduced percutaneously from the femoral artery. The proximal end was pre-shaped into a clockwise semicircular loop at obtuse angle to the long axis of the catheter. The tip was placed into the left aortic sinus and the single side hole was thereby directed towards the right. A single X-ray film was triggered in diastole from the $R$ wave of the electrocardiogram by a special electronic variable delay circuit. The possibility of unsuccessful arteriograms due to failure to observe the various features of the method, which are described in detail, is stressed. It is concluded that the technique should be simple to perform and of low risk in man.

The authors are indebted to Messrs. R. O'Kell and V. Coltart for invaluable technical assistance.

\section{REFERENCES}

Anlyan, W. G., Baylin, G. J., Fabrikant, J. I., and Trumbo, R. B. (1959). Surgery, 45, 8.

Arnulf, G., and Chacornac, R. (1958). Lyon Chir., 54, 212.

Bellman, S., Frank, H. A., Lambert, P. B., Littmann, D., and Williams, J. A. (1960). New Engl. J. Med., $262,325$.

Bishop, H. A., and O'Laughlin, B. J. (1961). Calif. Med., 94, 218.

Blair, E. (1961). Circulat. Res., 9, 333.

Boucek, R. J., Murphy, W. P., Jr., and Hernandez, F. A. (1961). Radiology, 76, 565.

Davies, J. G., and Michell, G. (1960). Clin. Radiol., 11, 214.

Frische, L. H., and Dotter, C. T. (1959). Dis. Chest, 35, 546.

Gurewich, V., Sasahara, A. A., Quinn, J. S., Peffer, C. J., and Littmann, D. (1961). Circulation, 23, 593.

Hase, O., and Deterling, R. A., Jr. (1957). S Surg. Forum, 8, 320.

Hopps, J. A., Don, C., Bousvaros, G. A., and Roy, O. Communication to the 4th Annual Conference of the International Federation for Medical Electronics, New York City, July 16 to 21, 1961.

Jackson, N. J., and Cobbold, R. (1961). Canad. med. Ass. J., 84, 1351.

Lang, E. K., and Sabiston, D. C., Jr. (1961). Radiology, 76, 32.

Lehman, J. S., and Debbas, J. N. (1961). Radiology, 76, 548.

Littmann, D., Dean, D. C., Crowley, F. B., Jr., Gilson, I. T., and Williams, J. A. (1961). Amer. J. Cardiol., 7, 570.

Nelson, S. W., Molnar, W., Christoforidis, A., and Britt, C.'(1960). Radiology, 75, 19.

Ödman, P. (1956). Acta Radiol., 45, 1.

Richards, L. S., and Thal, A. P. (1958). Surg. Gynec. Obstet., 107, 737.

Seldinger, S. I. (1953). Acta Radiol., 39, 368.

Sekelj, P., Brent, F., and Dunbar, S. (1961). Amer. J. Roentgenol., 85, 1088.

Sloman, G., and Jefferson, K. (1960). Brit. Heart J., 22, 54.

Sones, F. M., Jr. (1960). In 'Clinical Cardiopulmonary Physiology.' Ed. Gordon, Grune and Stratton, New York and London, 2nd Edition, page 130.

Williams, J. A., Littman, D., Hall, J. H., Bellman, S., Lambert, P. B., and Frank, H. A. (1960). New Engl. J. Med., $262,328$.

ADDENDUM

Since this paper was submitted for publication, a leading article in Circulation (1961, 24, 161) has called attention to the risk of inducing ventricular fibrillation with inadequate grounding of intracardiac electrodes. We have reason to believe that inadequate grounding of the Gidlund injection apparatus may have induced the ventricular fibrillation in the instance reported in this series, and work is now in progress to confirm this. 